\title{
A New Non-Centrosymmetricorganotin (IV) Hybrid Compound C5H14N2 [SnCl6] 2H2O: Crystal Structure And Optical Study Characterization
}

Nejeh Hannachi ( $\nabla$ hnejeh@yahoo.fr)

Faculty of Sciences, University of Sfax, B. P. 1171, 3000 Sfax, Tunisia.

Thierry ROISNEL

ISCR (Institut des Sciences Chimiques de Rennes)

Faouzi HLEL

Faculty of Sciences, University of Sfax, B. P. 1171, 3000 Sfax, Tunisia.

\section{Research Article}

Keywords: Organic-inorganic hybrid, Chemical synthesis, X-ray diffraction, Optical absorption.

Posted Date: August 26th, 2021

DOI: https://doi.org/10.21203/rs.3.rs-840421/v1

License: (c) (i) This work is licensed under a Creative Commons Attribution 4.0 International License.

Read Full License 


\section{A new non-centrosymmetricorganotin (IV) hybrid compound $\mathrm{C}_{5} \mathrm{H}_{14} \mathrm{~N}_{2}\left[\mathrm{SnCl}_{6}\right] 2 \mathrm{H}_{2} \mathrm{O}$ :}

\section{Crystal structure and optical study characterization}

\section{Najeh HANNACHI ${ }^{\text {a }}$;hierry ROISNEL ${ }^{\text {b }}$;Faouzi HLEL ${ }^{\text {a }}$}

${ }^{a}$ Laboratory of spectroscopic characterization and optics of materials, Faculty of Sciences, University of Sfax, B. P. 1171, 3000 Sfax, Tunisia.

bUniv Rennes, CNRS, ISCR (Institut des Sciences Chimiques de Rennes) - UMR 6226, F-35000 Rennes, France

\section{Abstract}

*Corresponding author: hnejeh@yahoo.fr

A new non-centrosymmetricorganotin (IV) hybrid compound ${ }_{5} \mathrm{H}_{14} \mathrm{~N}_{2}$ [ $\left[\mathrm{SnCl}_{6}\right] 2 \mathrm{H}_{2} \mathrm{O}$ was determined by single crystal X-ray diffraction at 150(2) K. Its crystal structure was solved by single crystal X-ray diffraction reveling that compound crystallizes in the orthorhombic system with Pbca space group with the following lattice parameters: $a=12.1486$ (15) $\AA, b=15.4571$ (17) $\AA, c=16.7610$ (18) $\AA$ with $Z=8$. The bonding between inorganic and organic entities in the compounds is realized by hydrogen bonding $\mathrm{O}-\mathrm{H} \ldots \mathrm{O}, \mathrm{O}-\mathrm{H} \ldots \mathrm{Cl}, \mathrm{NH} \cdot \bullet \mathrm{Cl}, \mathrm{N}-\mathrm{H} \ldots \mathrm{Cl}$ and $\mathrm{O}-\mathrm{H}$...Cl. Finally,UV-visible absorption measurements exhibit two absorption bands (226 $\mathbf{n m}$ and $262 \mathbf{n m})$. The optical band gap (Eg) is deduced to be $3.46 \mathrm{Ev}$.

Keywords: Organic-inorganic hybrid; Chemical synthesis; X-ray diffraction; Optical absorption.

\section{Introduction :}

The chemistry of organo-metal halide materials has developed belongs to the large the attention family has increased; present of a differences types de structures. This structures are built up from isolatedMX $\mathrm{M}_{6}$ octahedra, sharing, corners, edges, or faces to form two dimensional slabs (2D), one dimensional chains (1D) or zero dimensional clusters (0D) separated by the organic cations. This characterization due to a charge number of parameters and done their numerous applications such as solid state batteries, high ionic or mixed conductors, capacitors, including catalysis, biochemistry, magnetism and materials science [1-8].These organo-metal are the subject of various applied studies, thanks to their structural properties [9, 10], luminescence, semi-conductivity, ferroelectric and nonlinear optical activities [9-12].

A novel group of these crystals, containing hetero aromatic cations have been recently synthesized and characterized $[\mathbf{1 3}, \mathbf{1 4}]$. Since aromatic heterocyclic cations are characterized by a significant electric dipole moment, some halogenobismuthates (III) and halogenostannates(IV) containing these cations form strongly polar structures. The presence of the polar properties in these materials is usually a result of the organic cations dynamics, which 
play a key role in the induction of ferroelectricity. The results obtained from the literature for the ionic compounds group containing aromatic cations pave the way for the investigation of novel polar materials.

This valuable features of hybrids, open promising new pathways for the use in a very broad application areas.Tin, an element of group IV of the periodic table, has two valences, giving rise either to the formation of stannous compounds $\left(\mathrm{Sn}^{2+}\right)$ when it is bivalent, or to that of stannic compounds $\left(\mathrm{Sn}^{4+}\right)$ when it is tetravalent. Tin can also form organotin derivatives, called organotins, which are characterized by the number of direct bonds between tin and carbon. The properties of these organotins open up a wide range of applications for them. Among numerous families of Organo-metal halides complexes, we focus on some hexachlorostannates, such as $\left(\mathrm{C}_{8} \mathrm{H}_{12} \mathrm{~N}\right)_{2}\left[\mathrm{SnCl}_{6}\right]$ [15], $\left(\mathrm{C}_{7} \mathrm{H}_{10} \mathrm{~N}\right)_{2}\left[\mathrm{SnCl}_{6}\right]$ [16], $\left(\mathrm{C}_{5} \mathrm{H}_{7} \mathrm{~N}_{2}\right)_{2}$ [ $\left.\mathrm{SnCl}_{6}\right]$ [17], $\left(\mathrm{C}_{10} \mathrm{H}_{10} \mathrm{~N}_{2}\right)$ [ $\left.\mathrm{SnCl}_{6}\right]$ [18], $\left(\mathrm{C}_{7} \mathrm{H}_{12} \mathrm{~N}_{2}\right)_{2}\left[\mathrm{SnCl}_{6}\right] \mathrm{Cl}_{2} \cdot 1.5 \mathrm{H}_{2} \mathrm{O}[19]$.

Moreover, piperazine and substituted piperazine nuclei had constituted an attractive pharmacological scaffold present invarious potent marketed drugs. In fact, hybrid materials are traditionally used in medicine, with the presence of piperazine introduces a very important synthetic strategy discovery indrug due to its easy modifiability, proper alkalinity and water solubility[20-24].

In this context we undertake in our laboratory several systematic studies in search of competitive properties with less toxic metals. To the best of our knowledge, only few research studies have investigated the structure and properties of organic inorganic compounds based on $\mathrm{SnCl}$. In this context we report in this article, the Study of a new organic inorganic material and the characterization of hybrid materials hexachlorostannatebased ; A new organotin (IV) cyclohexane octachlorotin $\mathrm{C}_{5} \mathrm{H}_{14} \mathrm{~N}_{2}\left[\mathrm{SnCl}_{6}\right] 2 \mathrm{H}_{2} \mathrm{O}$.

\section{EXPERIMENTAL}

\subsection{Synthesis of $\mathrm{C}_{5} \mathrm{H}_{14} \mathrm{~N}_{2}\left[\mathrm{SnCl}_{6}\right] 2 \mathrm{H}_{2} \mathrm{O}$}

A 1-methylpiperazine solution (99\%; SIGMA ALDRICH; 2 mmoles) was added to a tin(IV) chloride solution $\left(\mathrm{SnCl}_{2} .2 \mathrm{H}_{2} \mathrm{O}\right)(98 \%$; SIGMA ALDRICH; 4 mmoles) in concentrated hydrochloric acid (37\%) in the presence of water $(20 \mathrm{ml})$. Were dissolved in aqueous solution of $\mathrm{HCl}(2 \mathrm{M} ; 37 \%)$ for a few minutes with agitation successive to ensure complete dissolution of the compound. Second, such solutions were slowly combined in an autoclave and kept at 95 ${ }^{\circ} \mathrm{C}$ under auto-genous pressure for $20 \mathrm{~h}$. After cooling these solutions for five days at room 
temperature, colourless single crystals suitable for an X-ray structure determination were obtained. Schematically the reaction is shown in the following equation:

\section{$\mathrm{C}_{5} \mathrm{H}_{12} \mathrm{~N}_{2}+\mathrm{SnCl}_{2} ; 2 . \mathrm{H}_{2} \mathrm{O}$}

\section{(HCl diluted)}

\subsection{Measurements}

All reagents and solvents were obtained from commercial sources and used without further purification.

\subsection{Single-crystal X-ray diffraction}

The study of a single-crystal X-ray data collection was performed on plate single crystal with a dimensions $(0.42 \times 0.39 \times 0.018 \mathrm{~mm})$ selected through an optical examination crystal of $\mathrm{C}_{5} \mathrm{H}_{14} \mathrm{~N}_{2}$ [ $\left.\mathrm{SnCl}_{6}\right] 2 \mathrm{H}_{2} \mathrm{O}$ subjected to single X-ray diffraction using a D8 VENTURE Bruker AXS diffractometer equipped with a (CMOS) PHOTON 100 detector using Mo Ka radiation ( $\lambda=0.71073 \AA$, multilayer monochromator). The data were collected at 150 (2) K reveals that this material crystallizes in the Orthorhombic system with Pbca space group with the following lattice parameters: $a=12.1486(15) \AA, b=15.4571$ (17) $\AA, c=16.7610$ (18) $\AA$ with $\mathrm{Z}=8$. Single crystal diffraction experiments were performed and the crystal structure was explored and refined down to $\mathrm{R}_{1}=0.021$ and $\mathrm{wR}_{2}=0.049$.

All calculations were made using the WINGX crystallographic suite of programs [25]. The crystal structure for this compound was determined by the direct method and refined using the SHELXL and SHELXS crystallographic software package, respectively [26,27]. The positions of nitrogen, oxygen and carbon atoms have been identified on the subsequent Fourier difference map. The basic crystallographic parameters and some details of the the measurements structural and refinement are summarized in Table 1. The molecular structure of the studied compound was drawn and presented using ORTEP-3 [28], DIAMOND [29], Mercury [30] and Gauss-view programs [31]. The fractional atomic coordinates and equivalent isotropic displacement parameters ( $\AA 2)$ are presented in Table 2;3.

Crystallographic parameters for the structural analysis reported in this work are also deposited in Cambridge Crystallographic Data Centre and can be freely accessed atwww.ccdc.cam.ac.uk (CCDC no. 1969512).

\section{4 .Optical measurement}


UV-Vis spectrum was recorded on an Ellice SLe164 Double BEAM UV-Vis spectrophotometer in the range $200-800 \mathrm{~nm}$ using methanol as solvent.

\section{Results and discussion}

\subsection{Structure properties description}

Fig.1illustrates the asymmetric unit of the structure drawn with $50 \%$ probability thermal ellipsoids. The structural property of the compound studied by using the X-ray diffraction (XRD) recorded at room temperature. The X-ray diffraction of the $\mathrm{C}_{5} \mathrm{H}_{14} \mathrm{~N}_{2}\left[\mathrm{SnCl}_{6}\right] 2 \mathrm{H}_{2} \mathrm{O}$ compound have been indexed, the atomic arrangement in the Orthorhombic system with Pbca space group. The packing of $\mathrm{C}_{5} \mathrm{H}_{14} \mathrm{~N}_{2}$. $\left[\mathrm{SnCl}_{6}\right] \cdot 2 \mathrm{H}_{2} \mathrm{O}$ viewed along (bc) plan created with DIAMOND; with mutually surrounded organic groups $\left[\mathrm{C}_{5} \mathrm{H}_{12} \mathrm{~N}_{2}\right]^{2+} /$ two water molecule and inorganic groups formed by octahedral isolated $\left[\mathrm{SnCl}_{6}\right]^{2-}$. The water molecules interact between the cation entities with hydrogen bonds; play important roles in stabilizing the crystal structure. Organic and inorganic sheets are linked together through extensive intermolecular interactions. In the layer, nitrogen atoms of each cations are oriented oward bases of two $\mathrm{SnCl}_{6}$ octahedral. Therefore, organic and inorganic groups connection by via H-bonds .

A projection along the baxis of the structure present aoctahedral layers isolated, $\left[\mathrm{SnCl}_{6}\right]^{2-}$, sandwiched between two layers of piperazinecations $\left[\mathrm{C}_{5} \mathrm{H}_{14} \mathrm{~N}_{2}\right]^{2+}$ (Fig.1.b) and two $\mathrm{H}_{2} \mathrm{O}$ entities. Indeed, the organic layer, observed $\mathrm{z} / \mathrm{c}=0$, is formed by the organic cations $\left[\mathrm{C}_{5} \mathrm{H}_{14} \mathrm{~N}_{2}\right]^{2+}$ and arranged parallel plane in the direction $\mathrm{b}$ (Fig.2).

Each inorganic chain is derived from isolated hexachloridestannate octahedrons and water molecules. Notice that, in the new structure, every plane defined by $\mathrm{SnCl}_{6}$ octahedrons and $\mathrm{H}_{2} \mathrm{O}$ molecules is approximately parallel to that for each nearest neighbor. Pairs of water molecule, form hydrogen bonds above and below one chloride ions $(\mathrm{Cl})$ at the edges of the $\mathrm{SnCl}_{6}$ octahedrons by means of one $\mathrm{O}-\mathrm{H}$...... Cl contacts stabilizing the layer structure. Chains formed by the interactions of $\left[\mathrm{SnCl}_{6}\right]^{2-}$ anions and $\mathrm{H}_{2} \mathrm{O}$ molecules with $\mathrm{O}-\mathrm{H}$.....Cl hydrogen bonds in the $(a, b)$ plane and view of organic layers showing the alternance of infinite stacked organic chains along the a-axis are given in Fig 2-a.

Each organic chain observed, is formed by the cations $\left[\mathrm{C}_{5} \mathrm{H}_{14} \mathrm{~N}_{2}\right]^{2+}$ interaction is interconnected via a one piperazin ion have a parallel chain structure were the $\mathrm{C}-\mathrm{C}$ and $\mathrm{C}-\mathrm{N}$ bond length values are 1.509(3)-1.519(3) ̊́ and 1.496(3)-1.505(3) $\AA$, respectively. The C-C-C, C-N-C and C-C-N angles are in the range between 109.47(16) ${ }^{\circ}$ at $111.32(4)^{\circ}$ (Table 4). The Bond length and angles values are in good agreement with bond lengths of other piperazin salts [32-34]. 
The examination of the structure shows the existence of two chains are separated by octahedral layer, $\left[\mathrm{SnCl}_{6}\right]^{2-}$. In $\left[\mathrm{SnCl}_{6}\right]^{2-}$ anion and in the described compound, the $\mathrm{Sn}^{\mathrm{IV}}$ atom is six-fold coordinated by six chlorine atoms forming a slightly distorted octahedral coordination geometry arrangement. Selected bond distances and angles are listed in Table 3. The equatorial angles values $\mathrm{X}_{\mathrm{E}}-\mathrm{Sn}-\mathrm{X}_{\mathrm{E}}$ deviate moderately from $90^{\circ}$.The bond $\mathrm{Sn}-\mathrm{Cl}$ distances and the $\mathrm{Cl}-\mathrm{Sn}-\mathrm{Cl}$ angles are in the range 2.404(2)-2.448(5) $\AA$ and 89.193(19)- 178.892(19) ${ }^{\circ}$, respectively, (Fig.1.c).. These values are in good agreement with those found for other hexachlorostannates (IV) $[35,36]$.

These values are in agreement with those observed in similar compounds [37-40].The bond angles within the anionic entity are for the most part consistent and agree well with earlier other studies containing isolated octahedral $\left[\mathrm{SnCl}_{6}\right]^{2-}$ anion and show a slight distortion from the ideal values of $90^{\circ}$ and $180^{\circ}$. The average values of the Baur distortion indices of $\left[\mathrm{SnCl}_{6}\right]^{2-}$ entities are calculated using the following equations (1) and (2) [41]: where d: (Sn-Cl) distance, a :(Cl$\mathrm{Sn}-\mathrm{Cl}$ ) angle , $\mathrm{m}$ : average value, $\mathrm{n}_{1}$ and $\mathrm{n}_{2}$ are equal to 6 and 12 respectively.

$$
I D(S n-C I)=\sum_{i=1}^{n 1=4} \frac{|d i-d m|}{n 1 d m}(1) \quad I D(C I-S n-C I)=\sum_{i=1}^{n 2=6} \frac{|a i-a m|}{n 2 d m}(2)
$$

While, the distance and angles distortion indices for octahedral $\left[\mathrm{SnCl}_{6}\right]^{2-}$ are $\mathrm{ID}(\mathrm{Sn}-\mathrm{Cl})=$ $0.021(7)$ and $\mathrm{ID}(\mathrm{II})=0.007$, and $\mathrm{ID}(\mathrm{Cl}-\mathrm{Sn}-\mathrm{Cl})=0.112(5)$, respectively. These Baur's distortion values indicate that the $\left[\mathrm{SnCl}_{6}\right]^{2-}$ octahedral;of the $\mathrm{Sn}$ metal is less distorted. This slight distortion is correlated to deformations resulting from hydrogen bonding interactions (Table 3).This distortion can be explained by the stereochemical inactivity of the $5 \mathrm{~s}^{2}$ lone pair of $\mathrm{Sn}$ (IV) and also by the fact of interaction of $\left[\mathrm{SnCl}_{6}\right]^{2-}$ octahedron with neighbors molecules by the means of different hydrogen bonds. A more complete listing of bond distances and angles is given in Table 4.

The hydrogen bonding interactions do not only affect the geometry of the $\left[\mathrm{SnCl}_{6}\right]^{2-}$ octahedra, they are also the main force guiding the overall molecular arrangement of the ions in the crystal lattice. So the examination of the structure has shown that the main feature of the atomic arrangement in this compound is the existence of infinite parallel layers composed of anionic and cationic groups, spared by distance $\mathrm{d}=1.870 \mathrm{~A}^{\circ}$ and linked together by $\mathrm{O}-\mathrm{H} \ldots \mathrm{O}$ and $\mathrm{O}-\mathrm{H} . . \mathrm{Cl}$ hydrogen bonds (Fig.3). In fact, the inorganic groups and the organic cations are held together by by hydrogen bonds of $\mathrm{NH} \cdot \cdots \mathrm{Cl}$.

Fig.3 shows that in each layer, the anionic entities $\left[\mathrm{SnCl}_{6}\right]^{2-}$ are interconnected via $\mathrm{O}-\mathrm{H} . . \mathrm{Cl}$ hydrogen bonds generated by the water molecules to build infinity chains developed along the b-axis direction .Moreover, the 1-methylpiperzine is inserted between these chains via the 
above mentioned additional $\mathrm{N}-\mathrm{H}$... O hydrogen bonds that give rise to this layer(Table 5). The hydrogen bonding interactions between these layers give rise to a three-dimensional network and add stability to the structure.Fig. 4 presents the $\pi \ldots \pi$ interaction follow a parallel-displaced configuration of cation aromatic ring.

\subsection{Optical properties}

The optical absorption spectrum of $\mathrm{C}_{5} \mathrm{H}_{14} \mathrm{~N}_{2}\left[\mathrm{SnCl}_{6}\right] 2 \mathrm{H}_{2} \mathrm{O}$ title compound measured at room temperature shown in Fig. 4 exhibits two distinct absorption bands centered at $226 \mathrm{~nm}$ and 262 $\mathrm{nm}$. This is very similar to results found in other previous studies in the literature containing organic-inorganic compound films [42-45].

The lower energy absorption peak at $262 \mathrm{~nm}$ is due to band gap absorption and it is assigned to the excitation of free electron-hole pairs within the $\left[\mathrm{SnCl}_{6}\right]^{2-}$ inorganic part. Under excitation, an electron is excited from the valence band to the conduction band, leaving a hole in the valence band. The electron transition back to the ground state that is the recombination of the electron and hole yields an emission, which suggests that the material behaves as semiconductor and is consistent with the dark red of the crystal [46-48].

The peak which occurred at $226 \mathrm{~nm}$ can be attributed to the absorption of the highest energetic level in the conduction band. The optical band gap (Eg) for 4-(ammonium methyl) pipyridinium hexachlorostanate (II) trihydrate can be determined by extrapolation from the absorption edge which is given by the following equation [49].

$(\alpha h v) n=A(h v-E g)(3)$ Where $\alpha$ is the absorption coefficient, A is constant, hv is the energy of light and $\mathrm{n}$ is a constant depending on the nature of the electron transition which takes different values depending on the mechanism of interband transitions $n=2$ and $1 / 2$ [50-51].

The best fit is obtained for $n=1 / 2$.

Indeed, the optical band gap was determined from the intersections of the extensions of the linear parts of the curves $(\alpha h v) 1 / 2$ with the energy axis. Therefore, the transition is indirect and the value of the optical band gap is judged 3, $46 \mathrm{eV}$ (Fig. 5).

\section{Conclusion}


In brief, this manuscript reports a novel organic-inorganic hybrid material with the formula $\mathrm{C}_{5} \mathrm{H}_{14} \mathrm{~N}_{2}\left[\mathrm{SnCl}_{6}\right] 2 \mathrm{H}_{2} \mathrm{O}$. This compound belongs to the Orthorhombic system with Pbca space group. Their structure contains a $\left[\mathrm{C}_{5} \mathrm{H}_{12} \mathrm{~N}_{2}\right]^{2+} /$ two water molecule and inorganic groups formed by octahedral isolated $\left[\mathrm{SnCl}_{6}\right]^{2-}$. The synthesis and structural elucidation have been clearly described, the structure is stabilized by a combination of intermolecular $\mathrm{O}-\mathrm{H} \ldots \mathrm{O}, \mathrm{O}-\mathrm{H} \ldots \mathrm{Cl}$, $\mathrm{NH} \cdot \cdots \mathrm{Cl}, \mathrm{N}-\mathrm{H} . . . \mathrm{Cl}$ and $\mathrm{O}-\mathrm{H} . . . \mathrm{Cl}$ hydrogen bonds. The optical properties were investigated by absorption measurement and show two absorption bands at $226 \mathrm{~nm}$ and $262 \mathrm{~nm}$ which can be corresponded to the $\pi-\pi^{*}$. 


\section{References}

[1] H. Zhao, J.E. Holladay, H. Brown, Z.C. Zhang, Metal chlorides in ionic liquid solvents convert sugars to 5-hydroxymethylfurfural, Science 316 (2007) 1597-1600.

[2] N. Chatani, H. Inoue, T. Ikeda, S. Murai, Ru(II)- and Pt(II)-Catalyzed cycloisomerization of u-Aryl-1-alkynes. Generation of carbocationic species from alkynes and transition metal halides and its interception by an aromatic ring, J. Org. Chem. 65 (2000) 4913-4918.

[3] G. Ferey, Microporous Solids: from organically templated inorganic skeletons to hybrid frameworks. ecumenism in chemistry, Chem. Mater. 13 (2001) 3084e-3098.

[4] R.J.H. Clark, C.S. Williams, The far-infrared spectra of metal-halide complexes of pyridine and related ligands, Inorg. Chem. 4 (1965) 350-357.

[5] J.G. Converse, R.E. McCarley, Chemistry of polynuclear metal halides. VI. Magnetic susceptibility studies of some niobium and tantalum halide cluster derivatives, Inorg. Chem. 9 (1970) 1361-1366.

[6] L. Protesescu, S. Yakunin, M.I. Bodnarchuk, F. Krieg, R. Caputo, C.H. Hendon, R. Xi Yang, A. Walsh, M.V. Kovalenko, Nanocrystals of cesium lead halide perovskites $(\mathrm{CsPbX} 3, \mathrm{X} 1 / 4 \mathrm{Cl}$, $\mathrm{Br}$, and I): novel Optoelectronic materials showing bright emission with wide color gamut, Nano Lett. 15 (2015) 3692-3696.

[7] T.M. Koh, K. Fu, Y. Fang, S. Chen, T.C. Sum, N. Mathews, S.G. Mhaisalkar, P.P. Boix, T. Baikie, Formamidinium-containing metal-halide: an alternative material for near-IR absorption perovskite solar cells, J. Phys. Chem. C118 (2014) 16458-16462.

[8] C. Sanchez, B. Julian, P. Belleville, M. Popall, J. Mater. Chem. 15 (2005) 3559- 3592.

[9] Ishihara T, Kanemitsu Y. Optical properties of low-dimensional materials. World Sci

Singapore.

[10] Papavassiliou GC. Three- and low-dimensional inorganic semiconductors.Prog Solid State Chem. 1997;25:125-270.

[11] Kondo T, Iwamoto S, Hayase S, et al. Solid State Commun. 1998;105:503-506.

[12] Guloy AM, Tang Z, Miranda B, et al. Adv Mater. 2001;13:833-837.

[13] Hall M, Nunn M, Beglev M, et al. ChemSoc Dalton Trans. 1986;6:1231-1238.

[14] Piecha A, Pietraszko A, Bator G, et al. J Solid State Chem. 2008;118:1155-1166.

[15] D.G. Billing, A. Lemmerer, M. Rademeyer, Bis(1-phenylethylammonium) hexachloridostannate(IV) and bis(2-phenylethylammonium) hexachloridostannate (IV), ActaCrystallogr. C63 (2007) m101em104.

[16] M. Rademeyer, A. Lemmerer, D.G. Billing, Bis(4-aminopyridinium) hexachloridostannate( IV) and bis(p-toluidinium) hexachloridostannate(IV), ActaCrystallogr. C63 (2007) m289em292.

[17] M. Rademeyer, Bis(benzylammonium) hexachlorotin(IV), ActaCrystallogr. C60 (2004) m55em56.

[18] Mohamed Saber Lassoued, Hussien H. Osman, Mohammed S.M. Abdelbaky, AbdelmajidLassoued, Salah Ammar, Abdelhamid Ben Salah, AbdellatifGadri, Santiago García-Granda 10.1016/j.jpcs.2018.05.024

[19] R. Hajji, A. Oueslati, F. Hajlaoui, A. Bulou, F. Hlel, Phase Trans. (2015) 1.

[20] R.S. Upadhayaya, N. Sinha, S. Jain, N. Kishore, R. Chandra, S.K. Arora, Bioorg. Med. Chem., 12 (2004) 2225.

[21] W. O. Foye, T.L. Lemke, D.A. William, Principles of Medicinal Chemistry, fourth ed., Williams and Wilkins, London, 1995.

[22] L. L. Gan, Y.H. Lu, C.H. Zhou, Chin. J. Biochem. Pharm., 30 (2009) 127.

[23] J. L. Cai, Y.H. Lu, L.L. Gan, C.H. Zhou, Chin. J. Antibiot., 34 (2009) 454.

[24] L. L. Gan, J.L. Cai, C.H. Zhou, Chin. Pharm. J., 44 (2009) 1361.

[25] L.J. Farrugia, WinGX suite for small-molecule single-crystal crystallography, 
J. Appl. Cryst. 32 (1999) 837e838.

[26] G.M. Sheldrick, SHELXS-97, Program for Crystal Structure Solution and

Refinement, University of Gottingen, Germany, 1997.

[27] G.M. Sheldrick, SHELXL-97, Program for Crystal Structure Solution and

Refinement, University of Gottingen, Germany, 1997.

[28] C.K. Johnson, ORTEP: a FORTRAN Thermal-Ellipsoid Plot Program for Crystal

Structure Illustrations, Report ORNL-3794, 1965.

[29] K. Brandenburg, Diamond. Visual Crystal Structure Information System.

Version 3.2i, Crystal Impact GbR, Bonn, Germany, 2012.

[30] C.F. Macrae, P.R. Edgington, P. McCabe, E. Pidcock, G.P. Shields, R. Taylor,

M. Towler, J. Van de Streek, J. Appl. Cryst. 39 (2006) 453 e457.

[31] A. Frisch, R. Dennington II, T. Keith, J. Milliam, A. Nielsen, A. Holder, J. Hiscocks, Gauss-view Reference, Version 4.0, Gaussian Inc., Pittsburgh, 2007.

[32] N.M. O'Boyle, A.L. Tenderholt, K.M. Langner, J. Comput. Chem. 29 (2008) 839e845.

[33] S. Guidara, A. Ben Ahmed, Y. Abid, H. Feki, Molecular structure, vibrational spectra and nonlinear optical properties of 2,5-dimethylanilinium chloride

monohydrate: a density functional theory approach, Spectrochim. Acta 127 (2014) 275e285.

[34] N. Elleuch, W. Amamou, A. Ben Ahmed, Y. Abid, H. Feki, Vibrational spectroscopic study, charge transfer interaction and nonlinear optical properties of Lasparaginium picrate: a density functional theoretical approach, Spectrochim. Acta. 128 (2014) 781e789.

[35] X. Song, R. Xue, S. Chen, Y. Yin, Bis(4-acetylanilinium) hexachloridostannate(IV), Acta Cryst. E67 (2011) m653.

[36] M. Rademeyer, Bis(benzylammonium) hexachloro-tin(IV), ActaCryst. C60 (2004) m55em56.

[37] H. Li, R. Sun, H. Shi, S. Huang, 2-(2Ammoniophenylamino)ethanaminiumhexachlorostannate(IV) monohydrate, ActaCryst. E61 (2005) m2088em2089.

[38] S. Bouacida, H. Merazig, A. Beghidja, C. Beghidja, Bis(cytosinium) hexachlorostannate(IV), ActaCryst. E61 (2005) m2072em2074.

[39] S. Bouacida, H. Merazig, A. Beghidja, C. Beghidja, Bis(adeninium) hexachlorostannate( IV) dichloride tetrahydrate, ActaCryst. E61 (2005)

$\mathrm{m} 1153 \mathrm{em} 1155$.

[40] S. Bouacida, H. Kechout, R. Belhouas, H. Merazig, T. Roisnel, Bis(3hydroxymethylanilinium) hexachloridostannate(IV), ActaCryst. E67 (2011)

m395

[41] A. Ertl, J. Hughes, F. Pertlik, F. Foit Jr., S.E. Wright, F. Brandst€atter, B. Marler, Polyhedron distorsions in tourmaline, Can. Mineral.40 (2002) $153 \mathrm{e} 162$.

[42]S. BelhajSalah, Mohammed S.M. Abdelbaky, Santiago García-Granda, K. Essalah, C.

Ben Nasr, M.L. Mrad / 10.1016/j.molstruc.2017.09.098

[43] Y. Zhou,J. Li, H. Liu, L. Zhao, H. Jiang. TetrahedronLett. 47 (2006) 8511-8514.

[44] A. Kessentini, M. Belhouchet, J.J. Suñol, Y. Abid, T. Mhiri, J. Luminescence. 149 (2014) 341-347.

[45] Rachid Hajji, Mohamed Amine Fersia, SawssenHajjib, FaouziHlela, Ali Ben AhmedcChemical Physics Letters 722 (2019) 160-172

[46] I. Feddaoui, Mohammed S.M. Abdelbaky, S. García-Granda, K. Essalah , C. Ben Nasr

M.L. Mrad Journal of Molecular Structure 1186 (2019) 31-38

[47] C. Hrizi, N. Chaari, Y. Abid, N.C. Boudjada, S. Chaabouni, Polyhedron. 46 (2012) 41- 46. 
[48] A. Kessentini, M. Belhouchet, J.J. Sunol, Y. Abid, T. Mhiri, J. Luminescence. 134 (2015) 28-33.

[49] A.C. Dhieb, A. Valkonen, M. Rzaigui, W. Smirani, J.Mol.Struct. 1102 (2015) 50-56.

[50] R. Branek, H. Kisch, Photochemical and Photobiological Sciences. 7 (2008) 40-48.

[51] J. I. Pankove, Prentice-Hall Inc. Englewood Cliff, New Jersey. (1971), 34-86. 
Figures
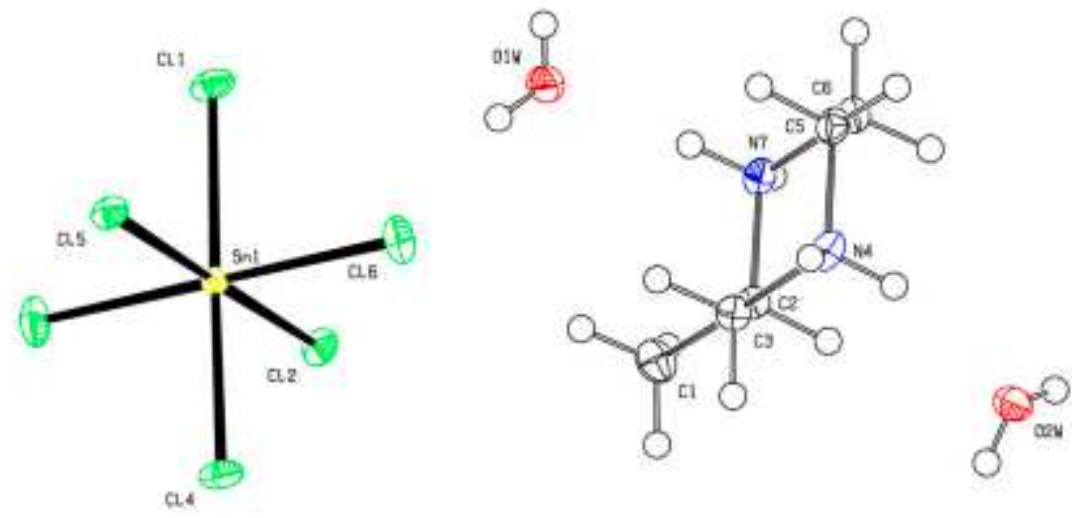

(a)
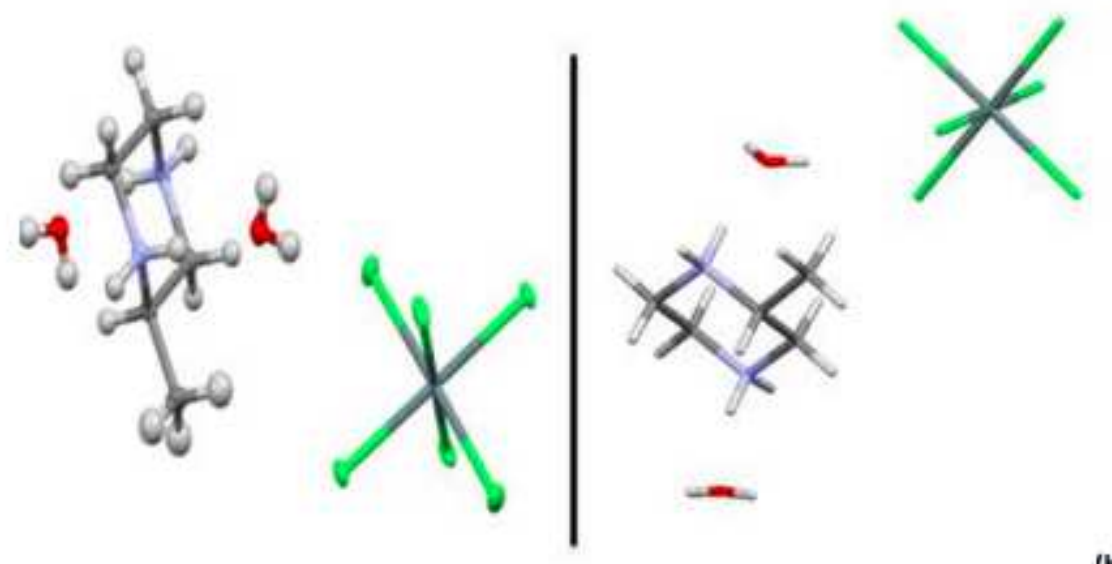

(b)

\section{Figure 1}

$(a-b):$ Ortep representation of the structure $\mathrm{C} 5 \mathrm{H} 14 \mathrm{~N} 2$. [SnCl6].2H2O with 1 with thermal ellipsoids at the $50 \%$ probability level. 


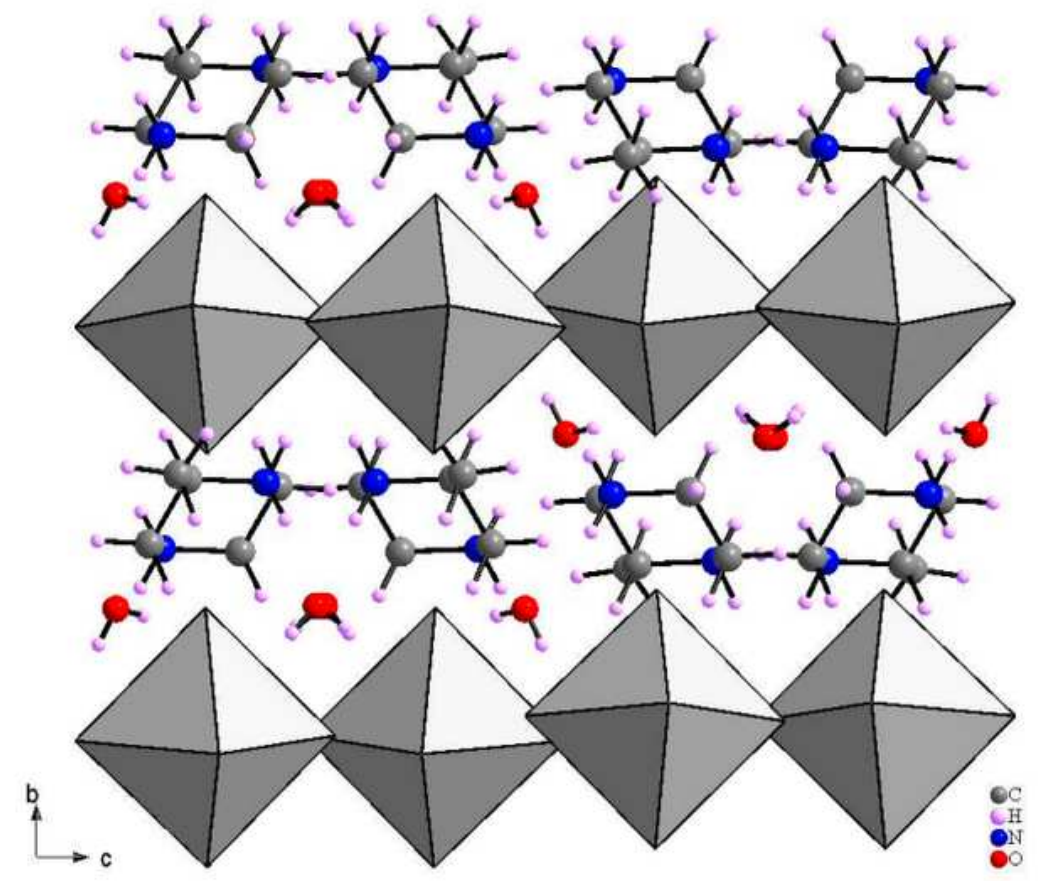

(a)
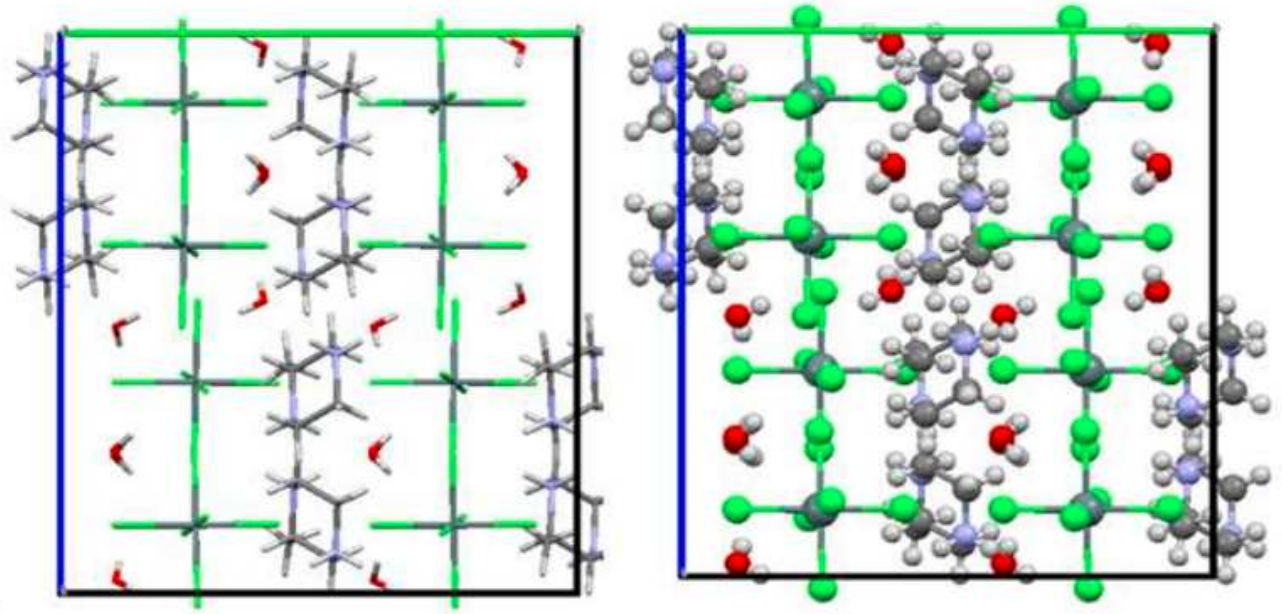

(b)

Figure 2

$(a-b)$ :Projection of the crystal packing of the title compound with $b$ direction 


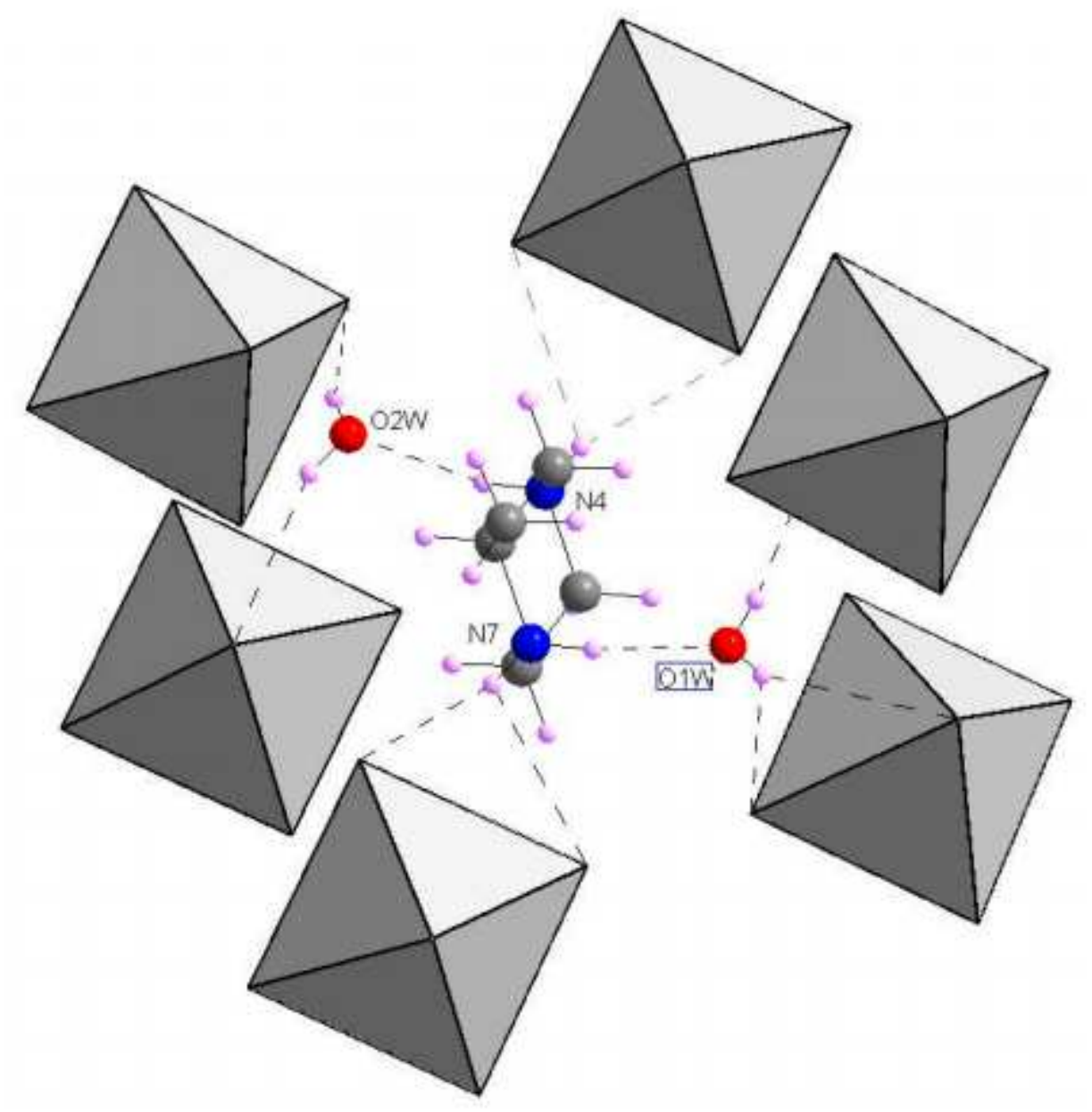

Figure 3

Projection of the hydrogen bonds in crystal with isolated [SnCl6] 2-octahedral. 


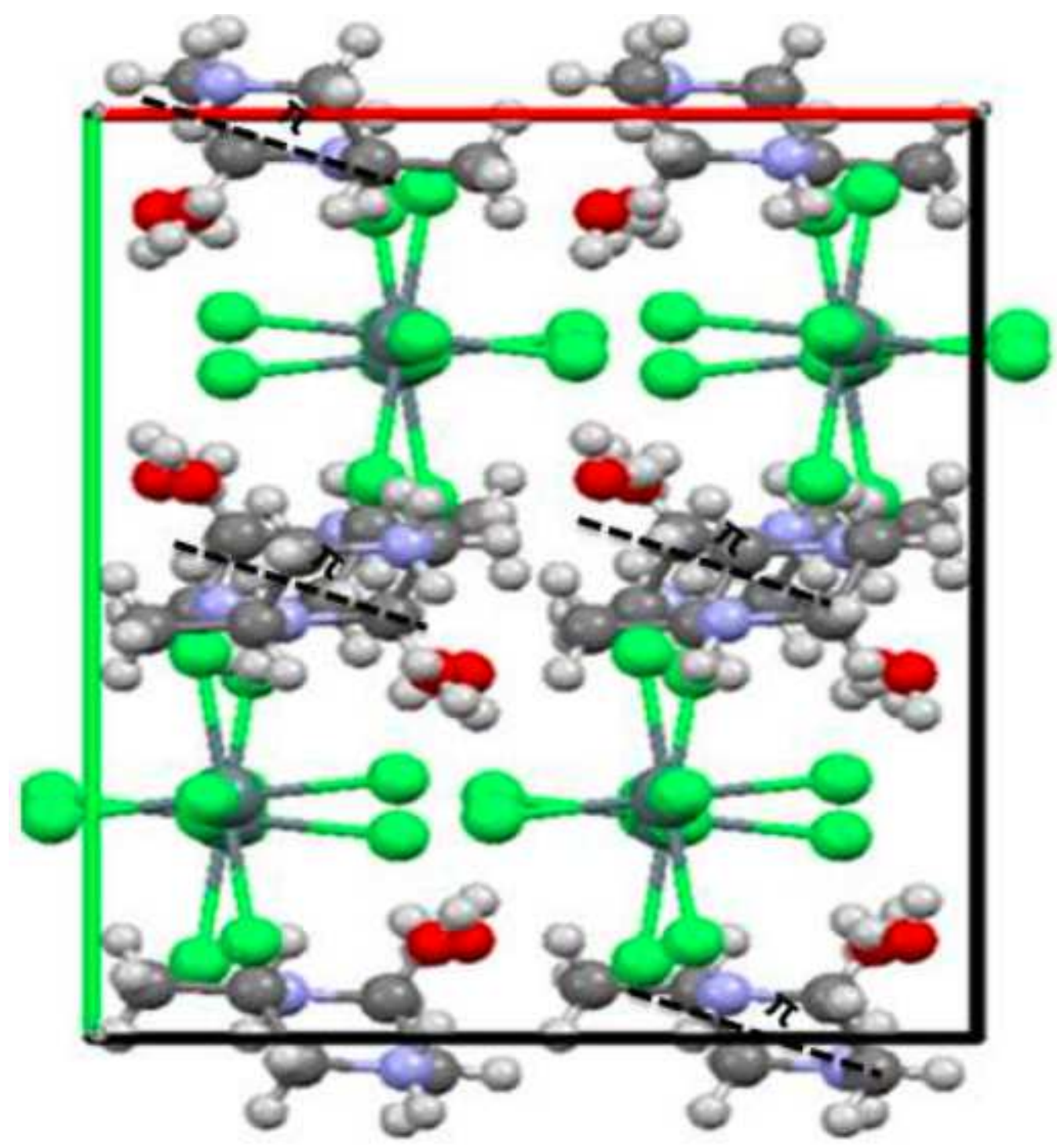

Figure 4

interaction motifs ( $\pi . . . \pi$ interaction) in cation groups. 

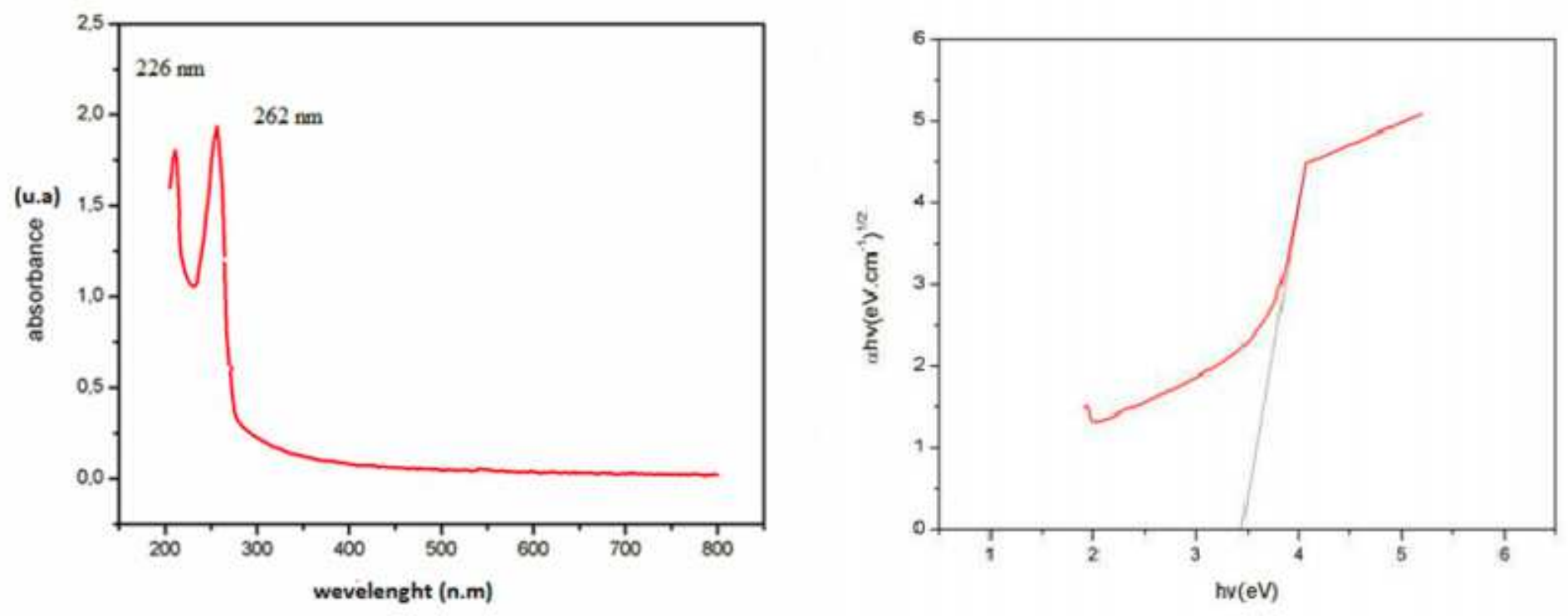

Figure 5

Absorption curves. energy gap optical properties.

\section{Supplementary Files}

This is a list of supplementary files associated with this preprint. Click to download.

- table.pdf

- NHR4150K17dec18D8VMocheckcif.pdf 